\title{
Writing Disability in ADHD Children
}

\author{
Gaillard François \\ University of Lausanne \\ Quartier Vincent \\ University of Lausanne \\ Roman Pascal \\ University of Lausanne
}

The psychological examination aims at objectifying the key symptoms of hyperactivity, i.e. attention and executive function disorders (in short, activation-inhibition control). The files of 237 patients from our consultations, aged between 5 and 17 years old and examined between 2004 and 2016, are analyzed retrospectively. Of whom 40 cases show the typical ADHD syndrome, mixed presentation, according to DSM-5 criteria.

These ADHD children and adolescents show not only a characteristic impulsivity on computerized attention tests, but also a deficit in the acquisition of writing, an early manifestation of their neurodevelopmental disorders. This association correctly classifies $82.4 \%$ of hyperactives and controls, a strong effect given the difficult diagnosis of ADHD syndrome.

Keywords: ADHD, hyperactivity, writing disability, sensory motor, neurodevelopmental disorder

\section{INTRODUCTION}

Attention Deficit Hyperactivity Disorder (ADHD) is defined by the American Psychiatric Association as a developmental deficit in executive function, modulated according to its onset over the course of life, depending on the degree of severity, and taking into account the association with other behavioural, personality and learning disorders. This set of difficulties often jeopardizes the child's schooling and can compromise the adult's training and career.

The syndrome is evoked by everyone: doctors, parents, teachers, specialists, but the diagnosis is ultimately based on the judgment of a practitioner who has few means of clinical evaluation. Scientific literature reflects the international concern of clinicians and researchers: 31,398 books, book chapters and scientific articles have already been published on ADHD syndrome according to Medline of September 1, 2017. The global prevalence of ADHD is estimated between 2.6 and $4.5 \%$.

As early as the 1980s, European neuropsychologists began a concerted effort to use computers to develop Kitap, a multifactorial attention assessment tool. The UNIL Institute of Psychology participated in the standardization of this test and then introduced it into its practice of child and adolescent counselling. 
Hyperactivity syndrome does not fit the notion of a disease. The phenotype is dominated by agitation and inattention, and behavioural disorders sensitive to the surrounding circumstances. As they grow up, hyperactive children manage their energies very poorly, both in their cognitive efforts and in their educational motivations (opposition, aversion to waiting, intolerance for deferred rewards, demotivation).

Initially very mobilizing from an educational point of view, the syndrome very often develops its comorbidities in the form of learning disorders: clumsiness, oral language disorders, specific difficulties in reading and mathematics acquisition. All aspects of writing (sensory and motor control of spelling, symbol writing, transcription of grammar, written expression) seem to be particularly affected in ADHD schoolchildren.

This study uses the Kitap test to highlight associations between attention mechanisms and cognitive processes in a local sample of children with classic ADHD (French-speaking Switzerland).

\section{METHOD}

\section{Population}

The population of patients who took the Kitap exam includes 237 children and adolescents aged 5 to 17 years (mean 10 years, 4 months; standard deviation 2 years, 6 months).

\section{Selecting the ADHD Group}

Complaints of attention deficit disorder were mentioned by more than one consultant in two. On the other hand, few of our consultants came to us with a diagnosis of hyperactivity. This is why we have adopted a strict definition of ADHD syndrome, mixed presentation: attention disorders and hyperactivity noted together in at least two different contexts by different observers: the doctor(s), the family, the teachers, the specialists. Exclusion criteria were severe congenital neurological disorder, acquired encephalopathy, global mental retardation, long-lasting hearing and vision disorders, severe disruption of family and social environment.

40 children and adolescents with ADHD were identified, an incidence of $17 \%$, a proportion well below the complaints of inattention.

\section{Control Groups}

The first control group consisted of the 77 patients whose records did not mention any of the three ADHD symptoms: neither attention deficit disorder, nor impulsivity, nor hyperkinesia. It allowed the comparison of children with and without ADHD in the same observation setting.

The second control group was chosen from the standardization of the Kitap test among 257 schoolchildren from the Lausanne region. 40 children and adolescents from the population were thus paired with ADHD subjects for age and gender.

\section{Hardware}

We digitized the data of the 237 consultants, taking into account age, sex, reports in the anamnesis, results of global intelligence tests and neuropsychological tests.

The Kitap test asked the child to respond as quickly as possible by pressing a button every time a certain target appeared on the screen. Reaction times (100ths of a second) and especially their variability during continuous trains of stimulation were recorded in the simple condition, in the "Go-no go" test consisting of answering for one target and inhibiting the answer for another, and finally in the "Distractibility" condition where, in addition, an avalanche of attractive figurines appeared that had to be ignored.

The other neuropsychological tests examined acquisition in the following areas: oral language understood, reading, writing, spelling, oral resolution of arithmetic problems, written calculation, graphic copies, spatial construction with materials, and reasoning on visuo-spatial data. Each score was transformed into a rank (very deficient, deficient, subnormal, normal, superior) according to the child's age scale. 


\section{Statistical Analysis}

Gender differences between samples with and without ADHD were calculated using the Chi- square method.

For continuous variables (age, intelligence scales, reaction time), Student's t-statistics between the same samples was applied.

For ordinal variables (attention quality, errors and omissions, reaction time variability, and neuropsychological tests), Somers' $\delta$ was preferred to Chi-square based on the observed distributions (e.g., the control group showed no significant deficits).

Based on the statistically significant differences, a binary logistic regression analysis was performed to separate the experimental group from the control group derived from standardization.

The first author is available for detailed information on the method.

\section{RESULTS}

\section{Comorbidities in the Clinical Sample}

Out of 237 consultants, 100 presented with one or another specific learning disability. Fig. 1 shows the overlap between the different disorders. Of the ADHD consultants, 27 children also presented with one or more disorders. 13 ADHD cases did not reveal an associated learning disability.

FIGURE 1

\section{LEARNING DISORDER COMORBIDITIES AND IMPACTS OF ADHD}

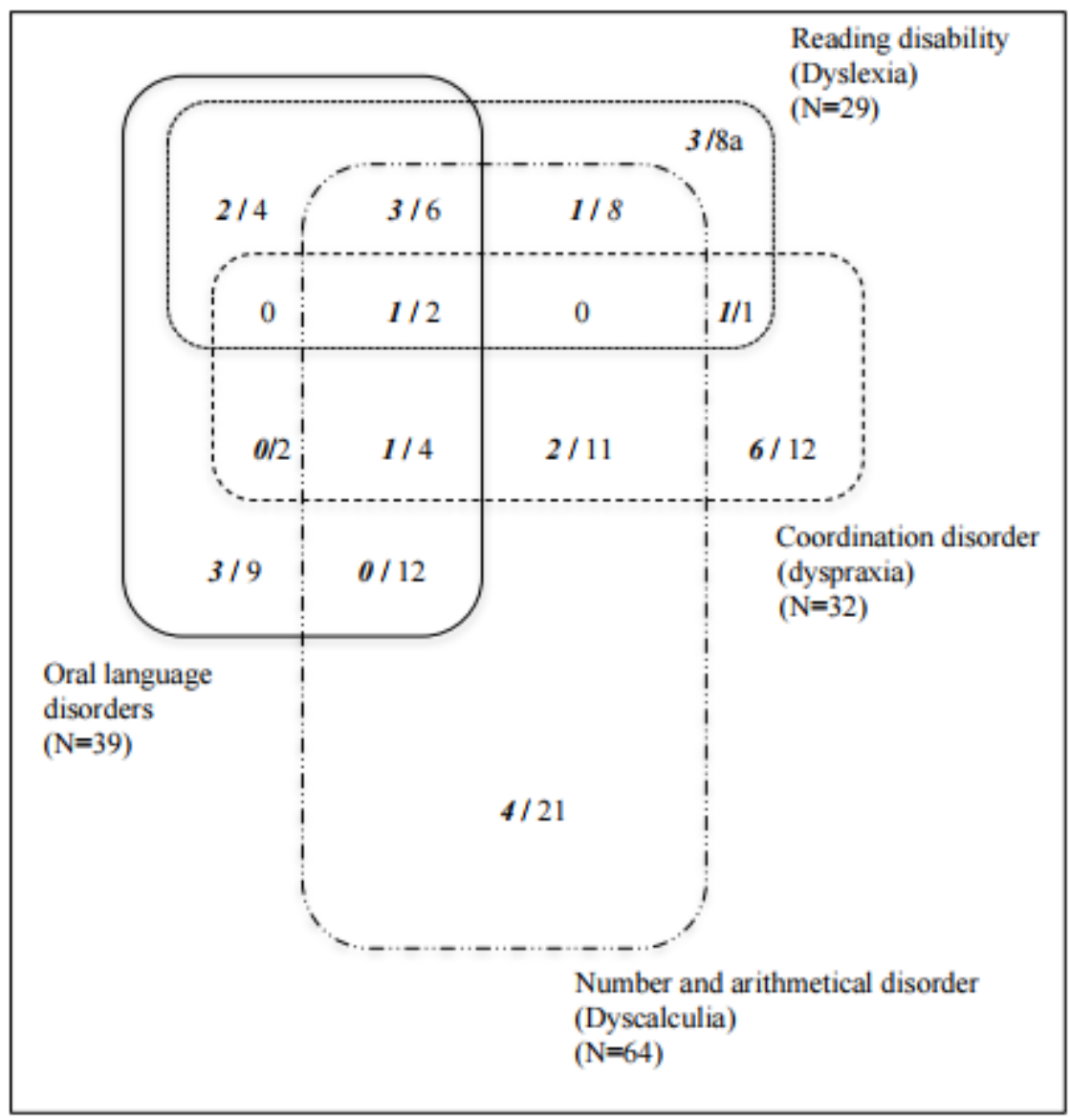

a: number of cases WITH ADHD / without ADHD; N: number of cases by disorder category 
The preponderant associations were for coordination and fine motor skills acquisition disorders (50\%) and language disorders, especially if complicated by reading disorders $(50 \%)$. In contrast, the association between ADHD and numeracy was much rarer.

We also note that ADHD syndrome was found in all co-morbidities (overlays in fig.1),

\section{Characteristics of the ADHD Sample}

Gender and Age

Table 1 shows that in our consultations we found 5.7 boys for 1 girl in the ADHD group, while there were only 1.4 boys for 1 girl in the group without $\operatorname{ADHD}(\mathrm{p}=0.004)$.

Children and adolescents with ADHD were younger than control subjects $(\mathrm{p}=0.001)$.

\section{TABLE 1 \\ GENDER AND AGE}

\begin{tabular}{lllc}
\hline & \multicolumn{1}{c}{ With ADHD } & \multicolumn{1}{c}{ Without ADHD } & p \\
Sex ratio & $34 \mathrm{M}: 6 \mathrm{~F}$ & $45 \mathrm{M}: 32 \mathrm{~F}$ & 0.004 \\
Age (months) & $\mathrm{m}=114.6 \mathrm{sd}=29.1$ & $\mathrm{~m}=133.8 \mathrm{sd}=30.0$ & 0.001 \\
\hline
\end{tabular}

M: male; F: female; $m=$ mean; $s d=$ standard deviation; $p$ : exact probability test.

\section{Global Intelligence Tests: WISC-IV (or K-ABC I and II)}

No overall intellectual functioning scale differentiated the group with ADHD from the group without ADHD. In particular, the working memory index, often deficient in attention problems, showed no significant difference.

\section{Reaction Time to the Kitap Attention Test}

There were no statistically significant differences between the groups. Overall, ADHD subjects were faster than control subjects. However, the Distractibility test in which distractors appear at the same time as the target has reversed the trend, with particularly high variability.

\section{Neuropsychological Test}

Regarding the quality of attention in the Kitap test, Table 2 shows that subjects with ADHD made more errors than controls in the Go-no go test $(\mathrm{p}=0.001)$, while being fast and alert (no omissions).

Table 2 highlights a "neurocognitive syndrome," which primarily affects written language (reading: $\mathrm{p}$ $=.001)$, writing $(\mathrm{p}<.001)$, spelling $(\mathrm{p}<.001)$, written calculation $(\mathrm{p}<.001)$, and "graphic copy" $(\mathrm{p}=.001)$. The "constructive spatial" factor, using concrete materials, cubes, triangles, as well as visual-spatial reasoning, did not differentiate the ADHD group from the expected standards. 
TABLE 2

NEUROPSYCHOLOGICAL TEST RESULTS FOR THE ADHD GROUP (RANKS)

\begin{tabular}{lcccccccc}
\hline & \multicolumn{9}{c}{ Observed frequencies } & & $\delta^{\mathrm{b}}$ & \multicolumn{2}{c}{$\mathrm{p} \mathrm{c}^{\mathrm{c}}$} \\
\cline { 2 - 6 } Kitap, Go-no go, errors & Ranks & 1 & 2 & 3 & 4 & 5 & & \\
\cline { 2 - 6 } Kitap, Distractibility, Variability & 7 & 2 & 9 & 21 & 1 & $-0,325$ & 0,001 \\
Oral language & 3 & 2 & 4 & 29 & 0 & 0,163 & 0,135 \\
Reading & 0 & 0 & 5 & 28 & 6 & $-0,072$ & 0,496 \\
Reading-deciphering & 1 & 5 & 6 & 8 & 0 & 0,493 & 0,001 \\
Reading comprehension & 1 & 1 & 5 & 14 & 0 & 0,240 & 0,130 \\
Writing & 1 & 1 & 4 & 14 & 0 & 0,211 & 0,197 \\
Spelling & 1 & 6 & 14 & 9 & 0 & 0,519 & 0,000 \\
Written calculation & 9 & 3 & 8 & 7 & 0 & 0,552 & 0,000 \\
Arithmetic, oral problems & 3 & 5 & 7 & 6 & 0 & 0,514 & 0,000 \\
Graphic copies & 1 & 2 & 8 & 13 & 4 & 0,172 & 0,173 \\
Constructive space & 0 & 8 & 7 & 14 & 0 & 0,404 & 0,001 \\
Visuo-spatial reasoning & 0 & 0 & 10 & 17 & 6 & 0,064 & 0,611 \\
\hline
\end{tabular}

${ }^{\mathrm{a}}$ : the expected frequencies are those of the normal distribution (Gauss curve); ${ }^{\mathrm{b}} \delta$ from Somers; ${ }^{\mathrm{c}}$ exact meaning.

\section{A Neurocognitive Model Put to the Test}

From Table 2, the quality of attention to the Kitap tests (Go-no go and Distractibility) as well as the "writing" and "graphic copy" neuropsychological tests were introduced in a binary logistic regression analysis, examining the discriminating power between the ADHD group and the normalization group. The sex and age of the subjects were controlled by matching.

The stepwise analysis (Wald) showed that the model as a whole was statistically validated ( $\mathrm{p}$

$<0.001)$. The factor "graphic copies" was excluded from the equation $(\mathrm{p}=0.489)$. The selected factors distinguished the two groups in 82.4 per cent of cases (Writing: $p=0.001$; Go-no go, errors: $p=0.016$; Distractibility, variability: $\mathrm{p}=0.050$ ). The Nagelkerke index reached 0.439 , which corresponds, according to Cohen, to a strong effect.

68 cases were included in this analysis (ADHD and controls). Of these, 56 cases were correctly classified, 12 cases were misclassified, 8 false positives and 4 false negatives. We therefore encountered the neurocognitive model in the population, either because there were ADHD cases in the control group, as the prevalence of ADHD syndrome would have predicted - or because the neuropsychological profile could exist without the hyperactivity. Conversely, 4 children with ADHD syndrome did not show the typical neurocognitive profile.

\section{CONCLUSION}

The study of co-morbidities shows that hyperactivity is revealed at an early age, in line with the predictors of the syndrome at the preschool level and with the search for solutions for children under 6 years of age. 
Our ADHD consultants are of normal intelligence. However, 2 out of 3 children suffer from learning disorders before compulsory schooling: fine motor and oral language disorders. This is followed by difficulties in the acquisition of writing and, at school, in reading, writing and written calculation.

Together with the objectification of impulsivity and attention irregularities by the Kitap test, early writing disorders constitute the phenotype of ADHD syndrome as it presents itself in our consultations. It distinguishes the hyperactive from the control in $82.4 \%$ of cases. From a neuropsychological point of view, the multiple role played by the differentiation, maturation and functioning of the fronto-striatal circuits is involved, in particular the regulation of the functions of the prefrontal cortex, the filtering of information coming from or going to the sensorimotor cortical areas, without neglecting the involvement of the limbic cortex: emotions, motivation, pleasure (reward), displeasure (aversion). This pattern is consistent with a neuropsychic disorder modelled by the small child's exchanges with those around him or her and which is part of his or her emotional and interrelational development.

Practical Implications

- ADHD syndrome is both behavioral and neuropsychic.

- ADHD syndrome does not appear as a result of educational and academic difficulties only.

- It is possible to predict the syndrome in more than $80 \%$ of cases based on neuropsychological signs.

- The syndrome is not only endogenous; it engages the relational and emotional world of the young child.

\section{ACKNOWLEDGEMENT}

This has been previously published in Swiss Medical Journal, March 6, 2019: 555-558. Translated \& edited by American Publishing Services (https://americanpublishingservices.com/).

\section{REFERENCES}

American Psychiatric Association. (2017, January). Annual Meeting Syllabus. Retrieved from http://www.psychiatry.org/psychiatrists/practice/dsm/updates-to-dsm-5/

Barkley, R.A. (Editor). (2006). Attention-deficit hyperactivity disorder: A handbook fordiagnosis and treatment (4th ed.). NewYork, N.Y.: Guilford Press.

Batstra, L., Nieweg, E.H., Pijl, S., Van Tol, D.G., \& Hadders-Algra, M. (2014). Childhood ADHD: A Stepped Diagnosis Approach. Journal of Psychiatric Practice, 20, 169-177.

Bledsoe, J.C., Semrud-Clikeman, M., \& Pliszka, S.R. (n.d.). Anterior cingulate cortex and symptom severity in attention-deficit/hyperactivity disorder. Journal of Abnormal Psychology, 122, 558565.

Boada, R., Willcutt, E.G., \& Pennington, B.F. (2012). Understanding the Comorbidity Between Dyslexia and Attention-Deficit/Hyperactivity Disorder. Topics in Language Disorders, 32, 264-284.

DuPaul, G.J., Gormley, M.J., \& Laracy, S.D. (2013). Comorbidity of LD and ADHD: Implications of DSM-5 for assessment and treatment. Journal of Learning Disabilities, 46, 43-51.

Habib, S., Kasprzak, B., LeGall, B., \& Joly-Pottuz, B. (2005, December 9). Behavioural disorders in hyperactivity in children: Inhibition deficit or reward system defect? Société de Neuropschologie de langue française, Paris. Retrieved from http://docplayer.fr/39651379-Tdah-troubles-ducomportement.html.

Masi, L., \& Gignac, M. (2017). ADHD and comorbidities in child psychiatry. Psychiatric pathologies, medical conditions, learning and coordination disorders. Annales Médico-Psychologiques, 175, 422-429.

McConaughy, S.H., Volpe, R.J., Antshel, K.M., Gordon, M., \& Eiraldi, R.B. (2011). Academic and social impairments of elementary school children with attention deficit hyperactivity disorder. School Psychology Review, 40, 200-25. 
Molitor, S.J., Langberg, J.M., Bourchtein, E., Eddy, L.D., Dvorsky, M.R., \& Evans, S.W. (2016). Writing Abilities Longitudinally Predict Academic Outcomes of Adolescents With ADHD. School Psychology Quarterly, 31, 393-404.

Monuteaux, M.C., Faraone, S.V., Herzig, K., Navsaria, N., \& Biederman, J. (2005). ADHD and dyscalculia. Evidence for independent familial transmission. Journal of Learning Disabilities, 38 , 86-93.

Pauli, W.M., O'Reilly, R.C., Yarkoni, T., \& Wager, T.D. (2016). Regional specialization within the human striatum for diverse psychological functions. Proceedings of theNational Academy of Sciences USA, 113, 1907-1912.

Peyre, H., Galera, C., van der Waerden, J., Hoertel, N., Bernard, J.Y., Melchior, M., \& Ramus, F. (2016). Relationship between early language skills and the development of inattention/hyperactivity symptoms during the preschool period: Results of the EDEN mother-child cohort. $B M C$ Psychiatry, 16, 2-12.

Sonuga-Barke, E.J., Sergeant, J., Nigg, J., \& Willcut, E. (2008). Executive dysfunction and delay aversion in attention deficit hyperactivity disorder: Nosologic and diagnostic implications. Child and Adolescent Psychiatry Clinics of North America, 17, 367-384.

Zimmermann, P., Gondan, M., \& Fimm, B. (2002). Test battery for attention testing for children (Kitap). Würselen (D): Psytest. 